\title{
Pulmonary vein stenosis: Plea for a multi-institutional registry
}

\author{
William M. DeCampli, MD, PhD
}

\author{
From the Department of Clinical Sciences, The University of Central Florida College of Medicine and the Heart \\ Center at Arnold Palmer Hospital for Children, Orlando, Fla. \\ Disclosures: Author has nothing to disclose with regard to commercial support. \\ Received for publication Sept 18, 2015; accepted for publication Sept 23, 2015; available ahead of print Oct 23 , \\ 2015. \\ Address for reprints: William M. DeCampli, MD, PhD, Heart Center, Arnold Palmer Hospital for Children, \\ 50 W Miller St, Orlando, FL 32813 (E-mail: william.decampli@orlandohealth.com). \\ J Thorac Cardiovasc Surg 2016;151:667-8 \\ $0022-5223 / \$ 36.00$ \\ Copyright (C) 2016 by The American Association for Thoracic Surgery \\ http://dx.doi.org/10.1016/j.jtcvs.2015.09.097
}

Pulmonary vein stenosis (PVS) in the pediatric patient is a challenging problem for which the cause is frequently unknown, the diagnostic criteria for intervention are uncertain, and the treatments are marginally effective. The 2-year survival in infants with this condition is about $60 \%$. In this issue of the Journal, Lo Rito and coworkers ${ }^{1}$ from the Hospital for Sick Children in Toronto report the outcomes of 31 patients who underwent surgical repair of multivessel PVS who also underwent preoperative computed tomography or magnetic resonance imaging (MRI). They report that smaller total "upstream" or "downstream" pulmonary vein cross sectional area and greater number of involved pulmonary veins were associated with poorer survival. Lo Rito and coworkers ${ }^{1}$ suggest that measurements derived from MRI and computed tomography can be used to predict disease severity and guide postoperative surveillance and "adjuvant" therapy in PVS.

The Toronto group has contributed significantly to our knowledge and management of pulmonary vein stenosis during the past decade, working comparably in the relevant areas of basic science, diagnostic modalities, and surgical techniques. $^{2-4}$ This article by Lo Rito and coworkers ${ }^{1}$ continues that contribution by reinforcing the value of MRI in imaging the PVs before intervention and by providing a valuable "hint" that preoperative PV size measurements are related to outcome. The task of definitively demonstrating this relationship is daunting for any single institution, however, because (1) PVS is relatively rare, (2) MRI and computed tomography are relatively recently used diagnostic modalities, and (3) MRI is not easily used in an important subset of the cohort, small infants. As such, with only 11 time-related events (deaths) in the cohort, the biphasic parametric riskhazard analysis used in this study was technically limited to a small number of covariates (2-5, depending on other characteristics of the model). Thus Lo Rito and coworkers ${ }^{1}$ could not take into account a myriad of additional covariates commonly associated with survival in complex congenital heart disease-covariates that, if included in a sufficiently large model, could significantly alter the odds ratios otherwise calculated for the included variables. It is prudent to

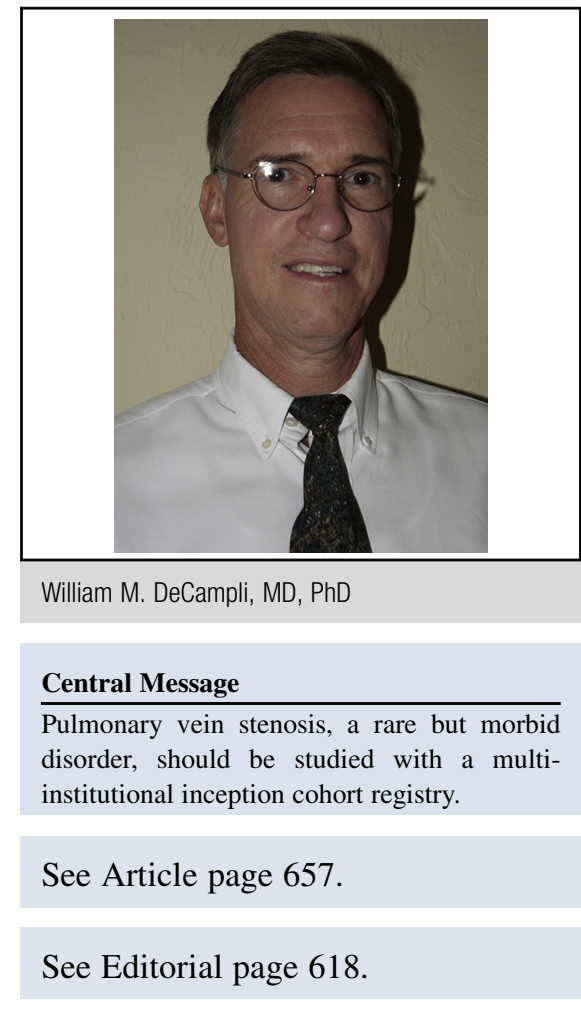

consider the results of Lo Rito and coworkers ${ }^{1}$ tentative until a larger study can be accomplished.

A Boston Children's Hospital study of PVS recently published in the Journal did not escape this dilemma, either. ${ }^{5}$ In their cohort of 49 patients, there were 14 deaths, and the median follow-up period was only 0.5 years. The risk analysis was limited to univariate tests, mostly log-rank tests on pairs of Kaplan-Meier curves. Relative to the Toronto group, ${ }^{1}$ the Boston group ${ }^{5}$ found a different set of covariate associations with death. In the Boston study, age younger than 6 months at operation, weight less than $3 \mathrm{~kg}$ at operation, and lesser preoperative right ventricular systolic pressure were associated with mortality, but the number of involved pulmonary veins was not. The study did not include pulmonary vein size measurements. As with the Toronto study, ${ }^{1}$ and for similar reasons, we should remain circumspect in interpreting these associations.

There are other important differences between these 2 studies. The descriptions of the operative techniques differed. Whereas both institutions pursued a "sutureless" technique, the Boston group ${ }^{5}$ described additional steps such as unroofing atretic veins, débriding all scar tissue out to first-order branches, and tacking vein edges to pericardium. Second, whereas the Toronto group ${ }^{1}$ described 
only 1 postoperative catheter intervention ( 1 in 28 operative survivors), Boston group ${ }^{5}$ performed such intervention in 29 of 49 patients $(59 \%)$, despite similar median ages at operation. Third, the Boston study ${ }^{5}$ used adjunctive chemotherapy in selected patients. Despite these differences, overall time-related survivals at 5 years were similar in the 2 studies- $64 \%$ in the Toronto study ${ }^{1}$ and $58 \%$ in the Boston study. ${ }^{5}$

The challenges in studying PVS encountered by these 2 high-volume, research- oriented programs leads us to suggest that PVS should be studied in a different way. Perhaps it is time to consider a multi-institutional mixed or inception cohort registry for PVS. The spring 2015 Society of Thoracic Surgeons Congenital Heart Surgery Database report lists 506 cases of PVS repair as the primary procedure between January 2011 and December 2014. If a study were to enroll just one-third of these subjects, it could accrue more than 40 subjects per year. Five years hence, with an anticipated 50 to 80 events (deaths), it would be possible to carry out more robust risk-hazard analyses. Inception cohort registries yield better studies than strictly retrospective or meta-analytic data sets, because subjects are prospectively enrolled and, ideally, all the requested data are acquired. In the early years of the registry, provisional analysis can be used to formulate "best practice" recommendations for nature and timing of diagnosis, intervention, and follow-up. If the enrolling institutions follow these recommendations, the quality of the registry improves further-the data become, in a sense, more controlled. This is exactly the strategy taken by the Congenital Heart Surgeons Society Data Center for studying anomalous aortic origin of a coronary artery, an anomaly that has an incidence not too different from, and an event rate much lower than, PVS. Perhaps the Congenital Heart Surgeons Society, which has the necessary resources in place, should engage in studying PVS - a rare, but disturbingly morbid, disorder.

\section{References}

1. Lo Rito M, Gazzaz T, Wilder TJ, Vanderlaan RD, Van Arsdell GS, Honjo O, et al. Pulmonary vein stenosis: severity and location predict survival after surgical repair. J Thorac Cardiovasc Surg. 2016;151: 657-66.

2. Kato H, Fu YY, Zhu J, Wang L, Aafaqi S, Rahkonen O, et al. Pulmonary vein stenosis and the pathophysiology of "upstream" pulmonary veins. J Thorac Cardiovasc Surg. 2014;148:245-53.

3. Kotani Y, Zhu J, Grosse-Wortmann L, Honjo O, Coles JG, Van Arsdell GS, et al. Anatomical risk factors, surgical treatment, and clinical outcomes of left-sided pulmonary vein obstruction in single-ventricle patients. J Thorac Cardiovasc Surg. 2014;149:1332-8.

4. Grosse-Wortmann L, Al-Otay A, Goo HW, Macgowan CK, Coles JG, Benson LN, et al. Anatomical and functional evaluation of pulmonary veins in children by magnetic resonance imaging. J Am Coll Cardiol. 2007;49:993-1002.

5. Quinonez LG, Gauvreau K, Borisuk M, Ireland C, Marshall AM, Mayer JE, et al. Outcomes of surgery for young children with multivessel pulmonary vein stenosis. J Thorac Cardiovasc Surg. 2015;150:911-7. 